\title{
Tropical Splenomegaly Syndrome in a Caucasian in Africa
}

\author{
M. N. LOWENTHAL,* M.B., CH.B., M.R.C.P.ED. ; M. S. R. HUTT, † M.D., F.R.C.P., F.R.C.PATH.
}

British Medical fournal, 1970, 3, 262-263

\section{Introduction}

In recent years there has been increased interest in the tropical splenomegaly syndrome and the subject has recently been reviewed (Pitney, 1968; Marsden and Hamilton, 1969; British Medical fournal, 1969). Outside Africa tropical splenomegaly syndrome has been described in the inhabitants of South Arabia (Fawdry, 1965), who anthropologically are caucasoid, in the Melanesians of New Guinea (Marsden et al., 1967; Pryor, 1967), who are negroid, and in Bengalis (Chaudhuri et al., 1956), who are caucasoid. No Caucasian (or "European") cases of tropical splenomegaly syndrome appear to have been reported from the African continent, and at least one observer with long experience in Africa states that he has yet to diagnose such a case (Lanzo, 1969). All the cases in Africa appear to have been in Negroes (Marsden et al., 1965; Lowenthal et al., 1966; Ratnesar et al., 1966; Watson-Williams and Allan, 1968). In a series from the Sudan specific mention is not made whether the patients were African or Arab (Mustafa, 1965).

We report here a case of tropical splenomegaly syndrome in a Caucasian resident in Africa.

\section{Case Report}

A 44-year-old woman of white South African (Afrikaner) descent was admitted to hospital in September 1966 with symptoms that were found to be due to acute calculous cholecystitis. For the previous 17 years she lived in rural parts of Zambia. For the first 15 years of her life she had lived in the Eldoret area of the Kenya highlands. After this she had resided for a year in Kampala and for some years in Mwanza on Lake Victoria before moving to what was then Northern Rhodesia. She stated that antimalarials had always been taken, at first quinine, then proguanil, and latterly Camoquin (amodiaquine hydrochloride) weekly or fortnightly. She denied ever having an overt attack of malaria though she had occasionally experienced feverish bouts during which a few more tablets of amodiaquine were taken. There was no history of alcoholism or jaundice. She had had five uncomplicated pregnancies, and five years previously had undergone hysterectomy.

She was a healthy-looking overweight woman who was apyrexial. Blood pressure was $140 / 80$. The only physical sign was massive splenomegaly, the spleen being firm and tender and the lower edge reaching the umbilicus. On further questioning she said she had experienced left-sided abdominal pain for the first time a few days previously. The liver was impalpable and there were no stigmata of hepatic cirrhosis or of biliary obstruction.

Investigations.- Hb $10.8 \mathrm{~g} .100 \mathrm{ml}$.; W.B.C. 5,600 (polymorphs $39 \%$, lymphocytes $57 \%$, monocytes $3 \%$, cosinophils $1 \%$ ); E.S.R. $60 \mathrm{~mm}$; platelets appeared in adequate numbers on a peripheral smear; serum bilirubin $0.9 \mathrm{mg} . / 100 \mathrm{ml}$; alkaline phosphatase 11.6 King-Armstrong units; prothrombin index $94 \%$; thymol turbidity 4 units; serum proteins $7.0 \mathrm{~g} . / 100 \mathrm{ml}$. (albumin $3.6 \mathrm{ml}$, globulin 3.4 g.); normal serum protein electrophoretic pattern; blood urea 24 mg./100 ml.; schistosomal complement fixation test anticomplementary; brucella and salmonella agglutinations negative; Kahn test negative; blood smear negative for malarial parasites on two occasions; no abnormalities or parasites in stool or urine. The malarial antibody titre with the fluorescent technique (Voller and Bray, 1962) was 1/800, compared with one of less than $1 / 100$ in a control serum. $X$-ray examination of the chest showed no abnormalities and of the gall bladder area showed

* Central Hospital, Ndola, Zambia.

t Professor of Pathology, Makerere University College, Kampala,
Uganda.

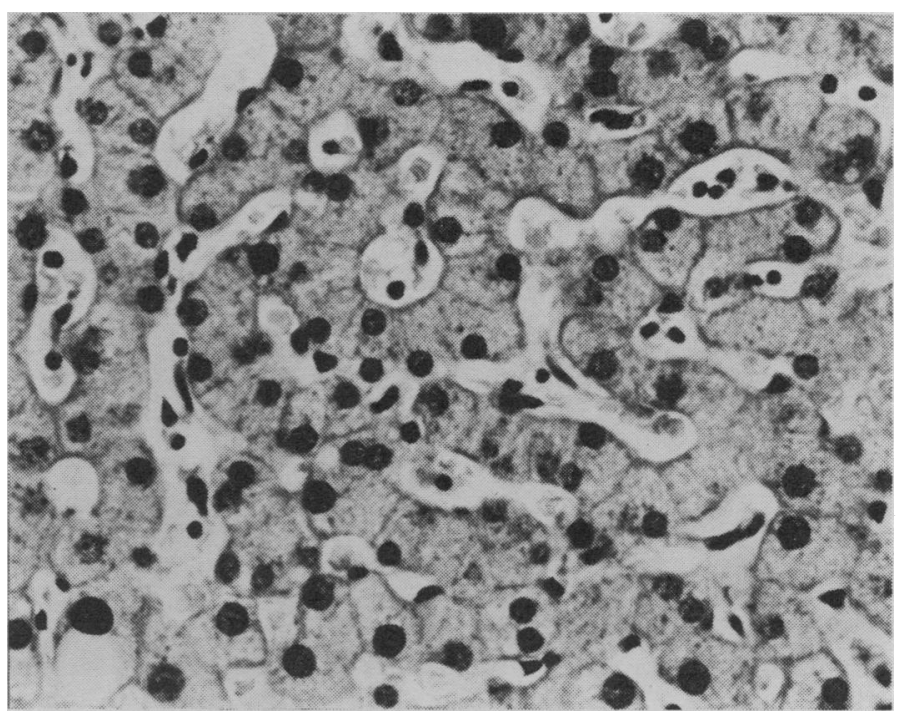

Kupffer cell hyperplasia with scattered lymphocytes in sinusoids. (H. and E. $\times$ 83).

opaque calculi. A liver biopsy (see Photomicrograph) showed Kupffer cell hyperplasia and scattered lymphocytes in the hepatic sinusoids.

The clinical condition settled with conservative treatment.

\section{Discussion}

The differential diagnosis in this case lies between the tropical splenomegaly syndrome (Marsden et al., 1965; Pitney, 1968; Marsden and Hamilton, 1969) and non-tropical idiopathic splenomegaly (Dacie et al., 1969). The clinical and pathological features of these two conditions are very similar and differ only in that the non-tropical cases are European and do not come from malarious areas. Except for the first 15 years of her life spent in the malaria-free Kenya highlands this patient had resided in malarious areas. She denied ever having malaria, though she gave a history of occasional fevers. The evidence for malaria in this case therefore rests on the raised malarial antibody titre. People exposed to malaria and taking prophylactics are known to be able to become infected and to transmit malaria by means of blood transfusion (Fisher and Schultz, 1969). The mechanism by which this situation could arise was elucidated 30 years ago (Sinton, 1939, quoted by Fisher and Schultz, 1969). Furthermore, chronic ill-health from unrecognized malaria has been reported in five cases in Uganda-three European, one Indian, and one Somali (Wilks et al., 1965). All these patients had raised malarial antibody titres and were improved by appropriate therapy; only one, however, had a palpable spleen.

These considerations lead us to believe that this patient had the tropical splenomegaly syndrome and that the syndrome is due to an unusual response to malaria (Charmot and Vargues, 1963; Marsden et al., 1965). Does this case throw any more light on the other factors which undoubtedly must play a part in the genesis of the disease? It shows that neither malnutrition nor severe malaria of falciparum type is essential to the development of tropical splenomegaly 
syndrome. The observations of Ziegler et al. (1969) indicate that there is no general fundamental abnormality of the lymphoreticular responses in patients who develop the syndrome. This suggests that either persistence or alteration of malarial antigen, or both, may be of prime importance. Dacie et al. (1969) suggested that an altered endogenous antigen may be the aetiological factor in non-tropical cases. If this is correct, persistent antigenic stimulus might explain the pathogenesis of both the tropical and the non-tropical cases.

We are grateful to Mr. A. W. Kirk Main, under whose care the patient was, and to Drs. D. S. Ridley, J. Fine, and Dale E. Wykoff for their assistance with this case. Dr. M. M. Nalumango, Permanent Secretary for Health, Zambia, gave permission for M.N.L. to publish.

Observations in this case were in part made possible by U.S. Army Medical Research and Development Command, Department of the Army, Research Grant DA-MD-49-193-63-C101, and by a grant from the Anglo-American Corporation and Roan Selection Trust groups of copper-mining companies.

Requests for reprints to M. N. Lowenthal, P.O. Box 166, Ndola, Zambia.

\section{REFERENCES}

British Medical fournal, 1969, 4, 4 .

Charmot, G., and Vargues, R. (1963). Semaine des Hôpitaux de Paris, 39, 1421 .

Chaudhuri, R. N., Saha, T. K., Basu, S. P., Mukheriec, A. M., and Chaudhuri, M. N. R. (1956). Indian fournal of Medical Research, 44, 305.

Dacie, J. V., Brain, M. C., Harrison, C. V., Lewis, S. M., and Worlledge, S. M. (1969). British fournal of Haematology, 17, 317.

Fawdry, A. L. (1955). Transactions of the Royal Society of Tropical Medicine and Hygiene, 49, 387.

Fisher, G. U., and Schultz, M. G. (1969). Lancet, 2, 716.

Lanzo, A. (1969). Transactions of the Royal Society of Tropical Medicine and Hygiene, 63, 150.

Lowenthal, M. N., Hamilton, P. J. S., Hutt, M. S. R., and Wilks, N. E. (1966). Central African fournal of Medicine, 12, 99.

Marsden, P. D., et al. (1965). British Medical fournal, 1, 89.
Marsden, P. D., et al. (1967). Bulletin of the World Health Organization, 36, 901 .

Marsden, P. D., and Hamilton, P. J. S. (1969). British Medical fournal,

1,99.
Mustafa, D. (1965). Fournal of Tropical Medicine and Hygiene, 68, 183.

Pitney, W. R. (1968). Transactions of the Royal Society of Tropical Medicine and Hygiene, 62, 717.

Pryor, D. S. (1967). Quarterly fournal of Medicine, 36, 321.

Ratnesar, V. C., Hathorn, M., Lahiri, H., Younn, S., and Kovi, J. (1966). Ghana Medical fournal, 5, 109.

Voller, A., and Bray, R. S. (1962). Proceedings of the Society for Experimental Biology and Medicine, 110, 907.

Watson-Williams, E. J., and Allan, N. C. (1968). British Medical Journal,

4, 793.
Wilks, N. E., Turner, P. P., Somers, K., and Markandya, O. P. (1965). East African Medical fournal, 42, 580.

Ziegler, J. L., Cohen, M. H., and Hutt, M. S. R. (1969). British Medical fournal, 4, 15.

\section{Preliminary Communications}

\section{Urographic Changes in Acute Papillary Necrosis in the Rat}

British Medical fournal, 1970, 3, 263-265

\begin{abstract}
Gumary: Intravenous high-dosage urography was performed in rats which had renal papillary necrosis induced with ethyleneimine or renal tubular necrosis produced with mercuric chloride. In both groups, nephrograms were abnormally persistent. In animals treated with ethyleneimine dense selective opacification of the necrotic renal pyramid occurred. It is suggested that this selective opacification may be a valuable radiological sign of recent renal papillary necrosis.
\end{abstract}

\section{INTRODUCTION}

Until recently intravenous urography was thought to be contraindicated in acute renal failure because it was considered dangerous and of little clinical value (Emmett, 1964). By using contrast media such as diatrizoate in high doses, however, information of diagnostic and prognostic significance may be obtained by this technique in renal failure (Schwartz et al., 1963; Chrispin, 1968; Mahaffy et al., 1968; Kelsey Fry and Cattell, 1970).

The present study stems from finding urographic abnormalities in infants suffering acute renal damage following severe gastroenteritis (Chrispin et al., 1970). In these three patients intravenous urography revealed nephrograms that were abnormally persistent and prolonged selective opacification of the renal pyramids. Repeat urograms on two of these infants some months later showed loss of renal papillae. To investigate this matter further we decided to induce renal papillary necrosis in rats to see if similar urographic changes could be produced. Our findings confirm that persistent opacification of the renal papilla occurs as a result of renal papillary necrosis. No such abnormal opacification of the renal papilla occurs where there is acute tubular necrosis alone.

\section{Materials AND Methods}

White male Wistar rats weighing between 250 and $300 \mathrm{~g}$. were used throughout. The animals were divided into two groups and treated as follows:

Group $A$ (eight animals).-Ethyleneimine (between 0.6 and $1.0 \mathrm{ml} . / \mathrm{kg}$. body weight of a $1 \%$ solution) was administered by intraperitoneal injection to each animal once only.

Group $B$ (seven animals).-Mercuric chloride (between 1.5 and $1.8 \mathrm{mg} . / \mathrm{kg}$. body weight of the mercuric ion) was administered by intraperitoneal injection to each animal once only.

Several untreated animals were used as controls.

Radiological studies were performed at one- and four-day intervals after injection of the nephrotoxins. The animals were anaesthetized with sodium pentobarbitone $(25 \mathrm{mg} . / \mathrm{kg}$. body weight) given by intraperitoneal injection and augmented by ether inhalation. Hypaque $65 \%$ (sodium and methylglucamine diatrizoate, Bayer) in a dose of between 2 and $2.4 \mathrm{ml}$. $/ \mathrm{kg}$. body weight was injected into a femoral vein, radiographs being taken at $1,3,10$, and 45 minutes after the injection. In addition further films were made at 90 minutes in some of the animals in group A. Each animal was subsequently killed and the kidneys were removed. These were examined macroscopically and then fixed in buffered formalin $(p \mathrm{H} \mathrm{7.0)}$ for 48 hours and secondarily fixed in mercuric chloride-formalin for six hours. The tissue was then embedded in paraffin wax and sections of 3-4 $\mu$ thickness were prepared. These were stained by Ehrlich's haematoxylin and eosin, periodic acid-Schiff, and Martius scarlet blue (M.S.B.). 